\title{
METHODS OF CALCULATING DEPRECIATION EXPENSES OF CONSTRUCTION MACHINERY
}

\author{
Dr Predrag Petronijević* \\ University of Belgrade, Faculty of Civil Engineering, Belgrade, Serbia \\ Dr Nenad Ivanišević \\ University of Belgrade, Faculty of Civil Engineering, Belgrade, Serbia \\ Dr Marina Rakočević \\ University of Montenegro, Faculty of Civil Engineering, Podgorica, Montenegro \\ Dr Dragan Arizanović \\ University of Belgrade, Faculty of Civil Engineering, Belgrade, Serbia
}

Depreciation expenses represent a significant part of total expenses of construction machinery. Precise calculation of depreciation expenses is often difficult or impossible. Straight line method of depreciation, which is commonly used in the calculation of ownership costs of construction machinery, does not give accurate results. This paper analyzes methods of depreciation expenses calculation, as well as their impact on the overall expanses of construction machinery and the impact on the cost per unit of material processed.

Keywords: depreciation, construction equipment, expenses

\section{INTRODUCTION}

In order to achieve successful management of a construction company and each of the construction projects it is essential to have an adequate approach to estimating and control of the expenses related to construction machinery. The revenue received must exceed the expenses incurred for work of a machine. A precise review of all the expenses has a key importance in the process of construction machinery selection [1]. Expenses of work hour increase during the lifetime of construction machinery. This process continues until the moment it is economically more viable to sell than to continue using the machine. This moment is considered as the end of the economic life time of the machine which can be much shorter than the physically possible life time i.e. the period in which a machine can perform its duties. This period can be increased by appropriate and regular maintenance and service.

\section{CALCULATION OF DEPRECIATION EXPENCES}

When calculating ownership expenses, the purchase value is a known amount, cost of capital can be accurately determined and so can insurance costs. The uncertainty lies in the calculation of depreciation expenses. The problem is even more significant having in mind that these depreciation expenses constitute $10 \%$ to $25 \%$ of the total expenses of machine work (figure 1 ).
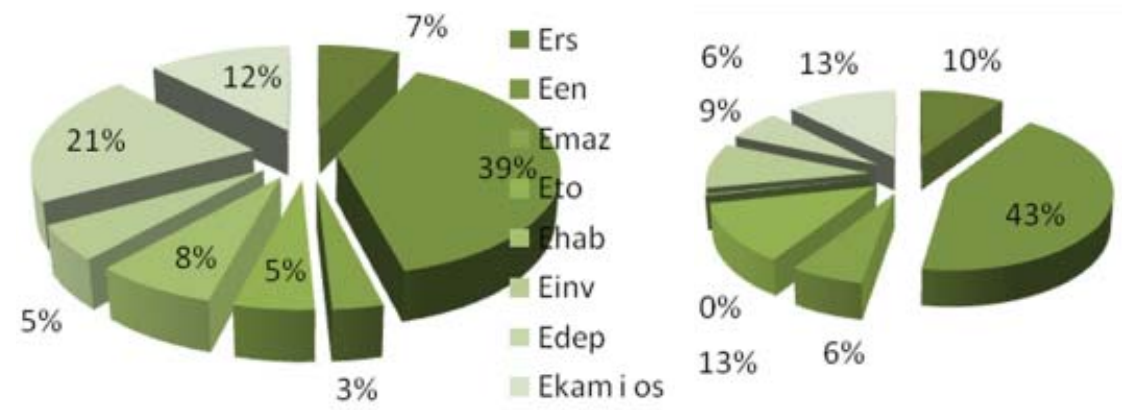

Figure 1 - Structure of expenses for nauler volvo zbt (Iert) ana excavator Caterpillar 320 
Depreciation represents the reduction of market value of a construction machine through time. The main causes of depreciation are:

- $\quad$ physical damages and wear and tear during work, and

- lowering of value due to elapsed time and functional outdate.

Depreciation value represents the difference between the market value of a construction machine at the time it was purchased and the market value when it is sold or destroyed.

Period of depreciation is the length of time which elapsed between the time a machine was purchased and the time it is sold or destroyed.

Depreciation expenses are calculated by dividing depreciation value (DEPvalue) with the period of depreciation (DEPperiod).

$E_{\text {dep }}=\frac{\text { DEPvalue }}{\text { DEPperiod }}$

When calculating depreciation expenses, some factors are explicitly given and precise while others are a result of estimating.

There is always a significant degree of uncertainty when depreciated value of a machine in a particular moment in time is defined, i.e. in the residual value which is defined as "the amount of money for which a machine can be sold in a particular moment in time". When calculating the depreciation expenses residual value is the future value on the end date of the period of ownership of a construction machine, so this value has to be estimated. Usually residual value has the biggest fall in the first years of the machine's work life, while this decrease is smaller as the machine gets older.

Estimation of the residual value of a machine in some future moment is made based on assumptions about the market conditions, the state of the machine, degree of its maintenance, needs of the owner, marketing activities and a whole number of different parameters which very often cannot be precisely described. Gunnar L. [2] has developed a model for approximation of the residual value of machines based on statistical data obtained from successfully finalized sales on the construction machine market. His central hypothesis was that it is possible, based on the data collected from the previous generation (G1 ), to predict the residual value of the current generation $(G)$ of machines (figure 2).

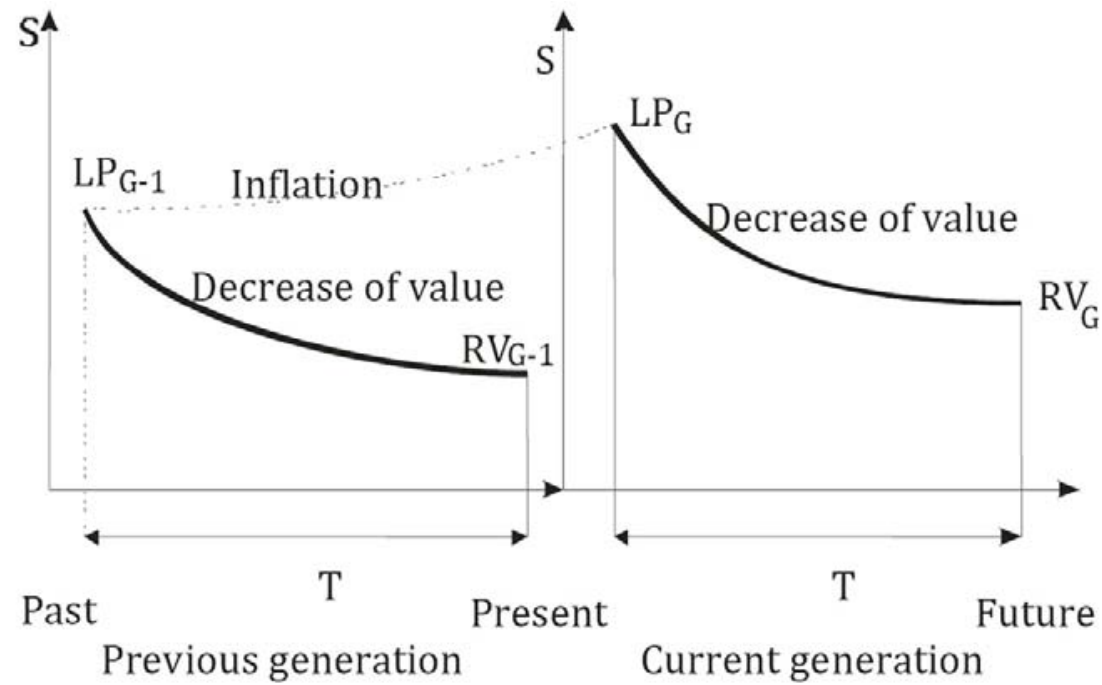

Figure 2 - Changes in the residual value

The model, based on the purchase price of the previous generation LPG-1, its residual value RVG-1 and the purchase price of the current generation LPG, predicts the residual value of the current generation RVG not only at present, but also in some future moment in time.

The goal of the research was to define, based on the previously mentioned input data, a regres- sion formula which would give an estimated residual value of a current generation construction machine. Formula should calculate the expected percentage of residual value RVP (Residual Value Percent) of the current generation (the ratio between the expected auction value and the recommended retail price). In total 11 regression formulas were analyzed, with the main requirement for the model that it can easily fit into the 
existing data, easily be interpreted, confirmed and used.

Based on previous analysis three regression models were proposed, with different complexity and level of accuracy. The conclusion was that RVP can successfully be predicted with a model based on a second degree polynomial. Also an important result of the research was that the most important factors which influence the residual value have been recognized.
The deficiency of such an approach lies in the fact that it is based on a large number of data on actually achieved auction prices on a narrowly defined second hand market. Also there are a significant number of variables which have to be linked to small territories and short periods of time. Another problem lays in the need to define a separate formula with different parameters for each type of construction machines.

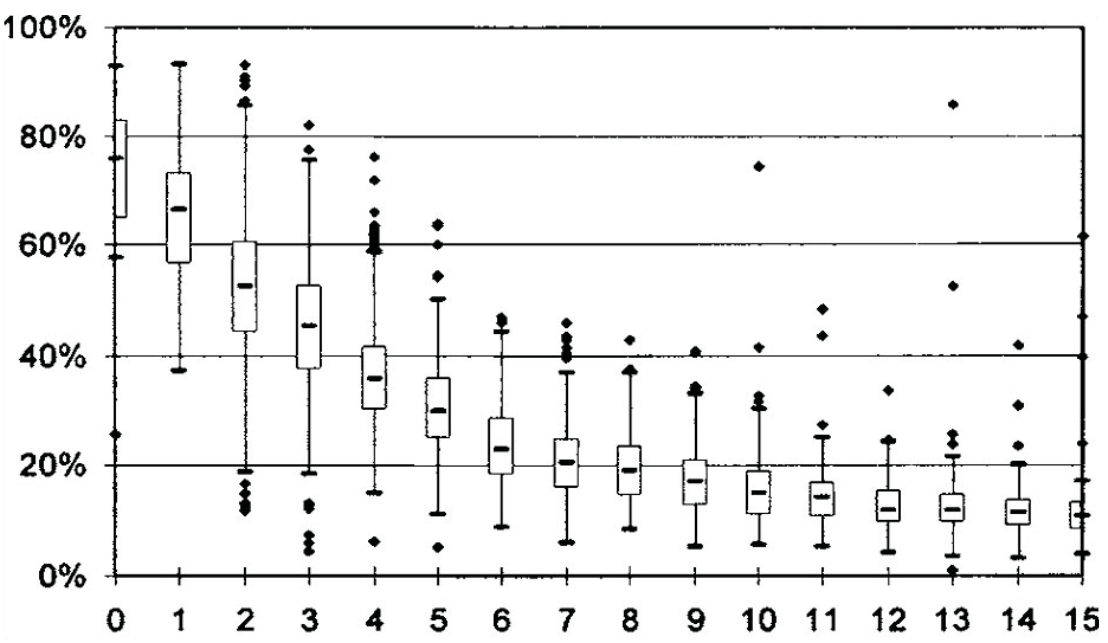

Figure 3 - Graph of RVP values compared to data gained from auctions

The approach given in paper [2] shows that, based on statistical data, it is possible to predict the sale price of a construction machine but it is not realistically achievable in practice due to insufficiency of historic data and the market structure. For this reason calculation of depreciation is usually done by applying other models, primarily based on the purchase price of a machine and its assumed life time.

In literature there are mainly three ways for calculating depreciation:

- Straight Line Method

- Sum-of-the-Years Method

- Declining Balance Method

\section{STRAIGHT LINE METHOD (UNIFORM LOWERING METHOD)}

Straight Line Method assumes uniform lowering of value during time. In general, annual depreciation rate $(R)$ is calculated using the following formula:

$R=\frac{1}{N}$ where $\mathrm{N}$ is the planned number of years the machine is going to be used (work life). The annual depreciation amount (D) is calculated according to the formula:

$D=R \cdot(P-F)$

where $P$ (Purchase Price) represents the price which was paid at the time $t$ when the company bought the machine (new or used) and $F$ represents the Salvage Value (market value of the machine when it is sold $\mathrm{N}$ years after it was bought).

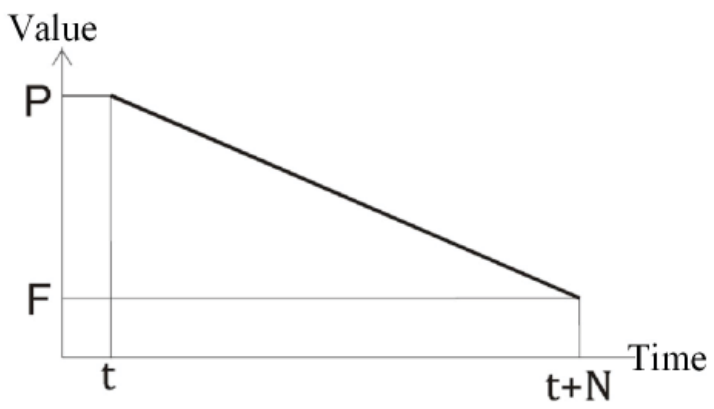

Figure 4 - The change of value during time applying linear (uniform) depreciation 
Due to the simplicity of calculations, this method is the most common method used in the calculation of expenses of construction machine's work hour. When using this method new and very old machines have the same annual depreciation.

\section{SUM-OF-THE-YEARS METHOD}

On the contrary to the linear depreciation used by the Straight Line Method, Sum-of-the-Years Method has a different depreciation amount for each year. When using the Sum-of-the-Years Method annual depreciation rate $(\mathrm{Rm})$ is calculated according to formula:

$$
R_{m}=\frac{N-m+1}{S O Y}
$$

where $\mathrm{N}$ is the number of years the company is the owner of the machine, $\mathrm{m}$ is a particular year for which the depreciation amount is calculated and SOY (Sum of the Years) is the sum of years the company owns the machine:

$S O Y=N+(N-1)+(N-2)+(N-3)+\ldots .+1$

Annual depreciation amount is calculated using the following formula:

$$
D_{m}=R_{m} \cdot(P-F)
$$

This method is closer to the realistic changes in the value of the machine. The value of the annual depreciation rate linearly changes, so the depreciation rate used for new machines is higher than the rate for older machines. So a bigger drop in its value a machine has when it is new, then when it is older.

\section{DECLINING BALANCE METHOD}

Declining-Balance Method is often used when calculating depreciation of machinery for companies' accounting purposes. This method enables changes in the rate of depreciation of a machine thorough the whole period of its usage, up to the end of its work life, when it reaches the Salvage Value which represents the bottom line of the machines depreciated value.

According to this method, annual depreciation rate depends on the remaining value of the machine in the accounting books. Machines which have a lower remaining accounting value will have a lower annual depreciation rate. The calculations are done according to formula:

$$
\begin{aligned}
& R=\frac{X}{N}, \\
& D_{m}=\left(B V_{m-1}\right) \cdot R \quad B V_{m}=B V_{m-1}-D_{m}
\end{aligned}
$$

where $\mathrm{N}$ represents the planned number of years the machine is going to be used (work life), $X$ is a value between 1,25 and 2,0 depending on the required speed of depreciation. Annual depreciation amount $(\mathrm{Dm})$ is calculated by multiplying the depreciation rate with the accounting book value of the machine for the previous year.

Accounting book value of a machine for a particular year $(\mathrm{BVm})$ is the accounting value of this machine for the previous year (BVm-1) lowered for the annual depreciation value $(\mathrm{Dm})$ of the machine.

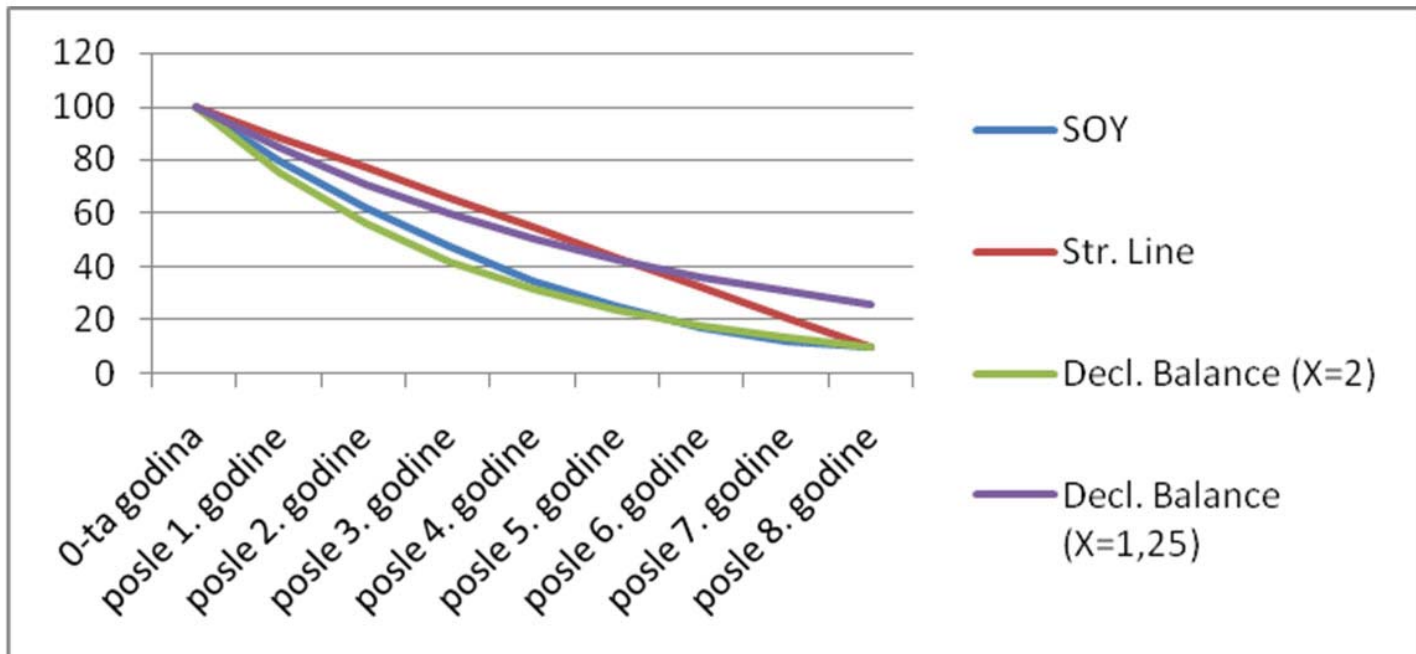

Figure 5 - Comparative graph for reduction of value through time 
Table 1 - Depreciation during 8 years for the three methods of calculation

\begin{tabular}{|c|c|c|c|c|c|c|c|c|c|c|}
\hline \multirow[b]{2}{*}{ 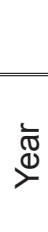 } & \multicolumn{3}{|c|}{ Rate of depreciation } & \multicolumn{3}{|c|}{ Annual depreciation amoun [\%] } & \multicolumn{4}{|c|}{ Value of the machine [\%] } \\
\hline & రે & 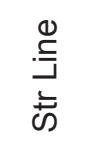 & 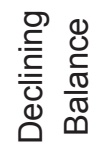 & రે & 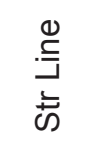 & 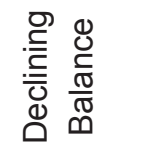 & $\begin{array}{l}\stackrel{\mathscr{E}}{=} \\
\stackrel{5}{\dot{5}}\end{array}$ & రે & 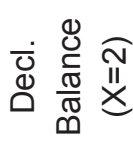 & 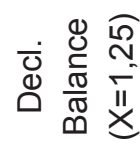 \\
\hline 1 & 0,22 & 0,13 & 0.25 & 20,00 & 11,25 & 25,00 & 100,00 & 100,00 & 100,00 & 100,00 \\
\hline 2 & 0,19 & 0,13 & 0.25 & 17,50 & 11,25 & 18,75 & 80,00 & 88,75 & 75,00 & 84,38 \\
\hline 3 & 0,17 & 0,13 & 0.25 & 15,00 & 11,25 & 14,06 & 62,50 & 77,50 & 56,25 & 71,19 \\
\hline 4 & 0,14 & 0,13 & 0.25 & 12,50 & 11,25 & 10,55 & 47,50 & 66,25 & 42,19 & 60,07 \\
\hline 5 & 0,11 & 0,13 & 0.25 & 10,00 & 11,25 & 7,91 & 35,00 & 55,00 & 31,64 & 50,68 \\
\hline 6 & 0,08 & 0,13 & 0.25 & 7,50 & 11,25 & 5,93 & 25,00 & 43,75 & 23,73 & 42,76 \\
\hline 7 & 0,06 & 0,13 & 0.25 & 5,00 & 11,25 & 4,45 & 17,50 & 32,50 & 17,80 & 36,08 \\
\hline 8 & 0,03 & 0,13 & 0.25 & 2,50 & 11,25 & 3,34 & 12,50 & 21,25 & 13,35 & 30,44 \\
\hline
\end{tabular}

INFLUENCE OF THE METHOD OF CALCULATING DEPRECIATION EXPENCES ON THE TOTAL EXPENCES OF THE MACHINE WORK HOUR

In order to analyze the influence of the method of calculating depreciation expenses on the total expenses of the machine work hour, testing was performed using calculations of the total expenses of the work hour and output of two machines. The first machine was excavator Caterpillar 320, engine power $140 \mathrm{~kW}$ with bucket size $0,9 \mathrm{~m} 3$. The second machine was hauler Volvo 25E engine power $140 \mathrm{~kW}$ and capacity $15 \mathrm{~m} 3$. Data on the purchase price, available work hours and usage of fuel and lubricants have been taken from document [3].

When comparing the three methods for calculating depreciation, it is clear that the uniform depreciation (St. Line) method is the easiest for calculating, but the results have the biggest variance from real values. The diagram given by $\mathrm{I}$. Gunar et al. [2] can be treated as a realistic diagram of depreciation. Newer the less this method of uniform depreciation is the method most frequently used in practice.

Sum-of-the-Years Method gives results close to real depreciation values. The calculations are simple, and the calculations of the depreciation rates do not depend on the type of machine or location where the machine will be sold.

Declining-Balance Method gives results close to the results of the SOY method, but the rate of depreciation can be changed. This method is very practical for accounting purposes.
According to the calculated values, the nearest to real values of depreciation is the Sum-of-theYears Method. As shown in Fig.1, depreciation expenses constitute around $21 \%$ of the total expenses of the work hour of hauler Volvo 25E and around $26 \%$ of the total expenses of the work hour of excavator Caterpillar 320. These values are calculated using the uniform depreciation method. When using the SOY method (method which sufficiently well describes the changes of the residual value during time, the participation of the depreciation expenses drastically changes with the age of the machine.

In the performed calculations, assumptions were that the work life of a machine is 8 years, the residual value at the end of work life is $10 \%$ of the purchase price and that the annual number of work hours is 1.500 . The depreciation expenses were calculated by dividing the annual depreciation calculated by using the Sum-of-the-Years Method and the Straight Line Method (uniform lowering method) with the annual number of work hours.

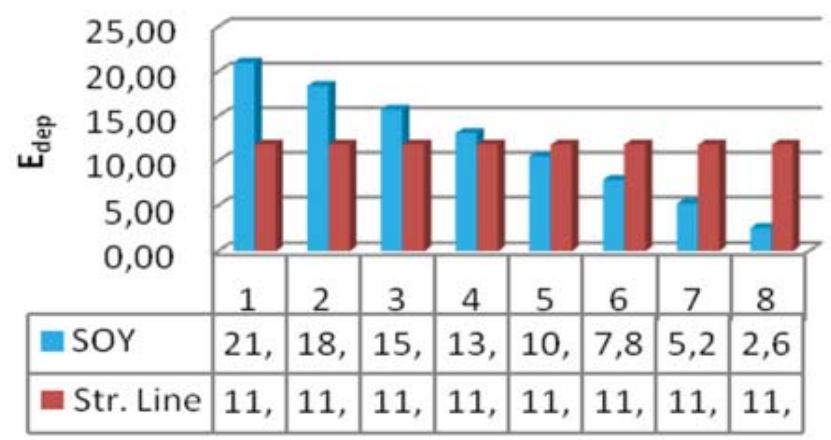

Figure 6 -depreciation expenses using SOY and Str. Line methods for excavator CAT 320 
In the first year, the depreciation expenses calculated using SOY method are almost twice the expenses calculated using uniform depreciation (Straight Line). When using the straight line method, total expenses of the work hour and the cost per unit of material processed are the same during the entire work life of a machine and the amounts are:

$\mathrm{K}_{\mathrm{h}}=58,30 € / \mathrm{h}$,

$$
\mathrm{C}_{\mathrm{jm}}=0,67 € / \mathrm{m} 3
$$

If the calculation of depreciation is done using SOY method, expenses of work hour and cost per unit of material processed, in the first year of work of the machine, are:

$\mathrm{K}_{\mathrm{h}}=74,86 € / \mathrm{h}, \quad \mathrm{C}_{\mathrm{jm}}=0,86 € / \mathrm{m} 3$

Using the same method, in the eight year the situation is opposite. The lowering of value of the machine is much smaller than in the first year, so the depreciation expenses are smaller than if Straight Line method was used:

$\mathrm{K}_{\mathrm{h}}=41,74 € / \mathrm{h}, \quad \mathrm{C}_{\mathrm{jm}}=0,48 € / \mathrm{m} 3$

In the middle of the work life of a machine there is no significant differences between depreciation expenses calculated by the two methods, although at that moment there is the biggest difference between the residual value calculated using SOY and Straight Line methods. The difference is $21 \%$ of the purchase price of the machine.

\section{CONCLUSION}

Previous data shows that calculations of depreciation according to the uniform method (Straight Line), although widely used, give results which are not in line with real life values. In the first half of the work life, depreciation expenses are lower than real, while in the second half of the work life depreciation expenses calculated by using this method are higher than real.

If the machine does not change its owner during its entire work life, this difference will not have significant importance. In case a company bought a new machine, used it half of its work life and then sold it, the expenses which the company has calculated through depreciation expenses will be much lower than the difference between the purchase price and its residual (auction) value in the middle of its work life.

Sum-of-the-Years Method gives results close to real depreciation values. The calculations are simple, and the calculations of the depreciation rates do not depend on the type of machine or location where the machine will be sold.

If the depreciation is calculated as the lowering of the residual value in the unit of time, in the middle of the work life of the machine, values calculated according to the uniform method (StraightLine) and SOY method are practically equal.

\section{REFERENCE}

1) P. Petronijević, "Optimizacija izbora građevinskih mašina”, $\mathrm{PhD}$ thesis, Belgrade, 2011..

2) Gunnar L. Christine M. Anderson, Michael Vorster, "Statistical Considerations for Predicting Residual Value of Heavy Equipment", Journal of Construction Engineering and Management, ASCE, July 2006 page 723 $-732$

3) USACE, "Construction Equipment Ownership and Operating Expense Schedule", 2007.

Paper sent to revision: 07.03.2012.

Paper ready for publication: 02.04.2012. 